\title{
YENİ BİR YÜKSEK HIZLI KALP DESTEK POMPASININ SAYISAL VE DENEYSEL ANALİİ
}

\author{
${ }^{1}$ Hasan ÇINAR, ${ }^{2}$ Rafet YAPICI \\ ${ }^{1}$ İskenderun Teknik Üniversitesi, Enerji Sistemleri Müh. Bl. İskenderun/ Hatay TÜRKİYE \\ ${ }^{2}$ Selçuk Üniversitesi, Mühendislik Fakültesi, Makine Müh. Bl. Selçuklu/Konya TüRKIYYE \\ 1hasan.cinar@iste.edu.tr, ${ }^{2}$ rafet@selcuk.edu.tr
}

(Geliş/Received:08.05.2017; Kabul/Accepted in Revised Form:12.07.2017 )

ÖZ: Sol ventriküler destek cihazları kalp yetmezliğine sahip hastalarda kullanılmaktadır. Rotodinamik kan pompalarının santrifüj, eksenel ve karışık akışlı olmak üzere üç tipi vardır. Eksenel akışlı kan pompaları yüksek hızlı fakat küçük çaplı pompalardır.

$\mathrm{Bu}$ çalışmada, tasarlanan karışık akışlı (yarı eksenel) bir kan pompasının Hesaplamalı Akışkanlar Dinamiği (HAD) yazılımıyla pompa karakteristiklerinin belirlenmesi ve bu karakteristiklerin deneysel olarak doğrulaması yapıldı. Pompanın tasarım noktası için 10000 dev/dak dönme hızı, 5 L/dak debi ve 100 mm-Hg basınç farkı değerleri seçildi. Pompa çarkı ve difüzörünün tasarımında pompa tasarım ve katı modelleme programları kullanıldı. Belirtilen tasarım verilerine göre katı modeli oluşturulan pompanın ANSYS Fluent programı ile simülasyonu yapıldı ve ilk tasarım değerlerinin sağlaması yapıldı. Debiye bağlı olarak basınç farkı, tork, cidar kayma gerilmesi ve hidrolik verim HAD yoluyla hesaplandı. Ayrıca bu çalışmada pompa çarkını tahrik eden milin, emme hattında ve basma hattında olduğu durumlar için ayrı ayrı HAD yazılımı ile pompa performansı belirlendi. HAD ile optimizasyon çalışmalarından sonra çarkın ve difüzörün nihai katı modelleri oluşturuldu. Bu iki elemanın prototipi, lazer sinterleme teknolojisi ile üretildi. Pompa gövdesi alüminyum malzemeden CNC dik işlem merkezinde imal edildi. Prototip pompanın deneysel performansı, tasarım ve tasarım basınç farkını sağlayan dönme hızında, su ve hacimce $\% 40$ gliserin- $\% 60$ su kullanılarak belirlendi. Su için HAD ve deney sonuçları kullanılarak debi-basınç farkı eğrileri oluşturuldu ve tasarım noktasında başlangıç tasarım değerinden 8 torr eksik basınç verdiği belirlendi. HAD sonuçlarına göre; pompa çarkını tahrik eden milin emme hattında veya basma hattında olmasının basınç farkına ve akış çizgilerine etkisi olmadığı görüldü.

Anahtar Kelimeler: HAD, Kalp pompası, Karışık akışlı pompa, Sol ventriküler destek cihazı

\section{Numerical and Experimantal Analysis of A New High-Speed Heart Assist Pump}

ABSTRACT: Left Ventricular assist devices are used in patients with heart failure. There are three types of rotodynamic blood pumps: centrifugal, axial and mixed flow. Axial flow blood pumps have high speed but they have small diameter pumps.

In this study, Pump characteristics were determined with the Computational Fluid Dynamics (CFD) software of a designed mixed-flow (semi-axial) blood pump and pump characteristics were experimentally verified. For the design point of the pump, $10000 \mathrm{rpm}$ rotation speed, $5 \mathrm{~L} / \mathrm{min}$ flow rate and $100 \mathrm{~mm}-\mathrm{Hg}$ pressure difference values were selected. Pump design and solid modeling programs were used in the design of the pump impeller and diffuser. The pump having a solid model according to design data specified was analyzed with the ANSYS Fluent and verification of the initial design values was made. Depending on the flow rate, the pressure difference, torque, wall shear stress and yield were calculated by CFD. In addition, the pump performance was determined by CFD software separately for the case where the pump is driven by the shaft, the suction line and the discharge line. After optimization study with CFD, the final solid models of the impeller and the diffuser were generated. The 
prototypes of these two elements were produced by laser sintering technology. The pump casing was made from aluminum material at the $\mathrm{CNC}$ vertical machining center. The experimental performance of the prototype pump was determined by water and volume of $40 \%$ glycerin- $60 \%$ water at the rotational speed providing design and design pressure difference. Flow-pressure difference curves were constituted using CFD and experimental outputs for water. It has been determined that the initial design value of the design point is less than 8 torr. According to CFD outputs; the presence of the shaft that drives the pump impeller on the suction line or the discharge line has no effect on the pressure difference and the flow line.

Key Words: CFD, Heart pump, Mixed flow pumps, Left ventricular assist device (LVAD)

\section{GİRIŞ (INTRODUCTION)}

Kalp rahatsızlıkları içinde kalp yetmezliği önemli bir yer tutar. Kalp yetmezliğinde, kalp birçok sebepten kaynaklanabilecek bozukluklardan dolayı pompalaması gereken miktarda kanı vücuda pompalayamaz ve hastalık genellikle ölümle sonuçlanır. Kalp yetmezliğinde en etkili tedavi yöntemi kalp transplantasyonudur (TX). Ancak uygun vericinin bulunamaması, bekleme süresinin uzun olması gibi sebeplerden dolayı TX her zaman mümkün olamamaktadır. Böyle durumlarda mekanik destek cihazları hayatidir. Mekanik destek cihazlarının amacı hastayı TX'e kadar yaşatmak ya da TX'in mümkün olmadığı hastalarda kalıcı tedavi sağlamaktır (Eğrican ve diğ., 2010). Türkiye'de 2014 yılına kadar kalp nakli bekleyen hasta sayısı 498'dir ve 2014 yılına kadar kalp nakli yapılan hasta sayısı 259'dur (Taneri, 2014). Bu sebeplerden dolayı mekanik destek cihazları üzerine çalışmalar insan hayatı açısından oldukça önemlidir. Genel olarak yapay kalp pompaları iki ana özelliğine göre sınıflandırılabilir. Akış tipine göre; pulslu pompalar, dönel (rotodinamik) pompalar, hacimsel (volumetrik) pompalar olarak sinıflandırılabilir (Kim ve diğ., 2012). Pompanın amacına göre; tamamen yapay kalp (TAH) veya bir ventriküler sisteme yardımcı (VAS) olarak sınıflandırılabilir (Kim ve diğ., 2012). Dönel sürekli akışlı kan pompaları; eksenel, santrifüj ve karışık akışlı olmak üzere üçe ayrılır. Dönel pompalarda bulunan çark mekanik enerjiyi akışkana aktarır. Dönel pompaların sınıflandırılması debi, dönme hızı ve basınç kullanılarak hesaplanan özgül hıza göre yapılır. Genellikle, santrifüj kan pompalarının dönme hızı 2000-4000 dev/dak'dır. Eksenel kan pompalarının hızı 6000-12000 dev/dak'dır.

Günümüze kadar çeşitli dönel kan pompaları geliştirilmiş ve klinik olarak kullanılmıştır (Burke ve diğ., 2001; Wood ve diğ., 2005). Bu cihazlar tamamen kalbin yerini almaz, sol ya da sağ karıncık ile paralel olarak çalışır(Chua ve Su, 2011). Mekanik destek cihazları uzun süreli kullanım için kompakt boyut, biyo-uyumlu ve dayanıklı olmalıdır (Kim ve diğ., 2012). Bunun yanında hemoliz ya da trombis gibi kan hasarı oluşturmamalıdırlar. Kalp pompası tasarımında karşılaşılan en büyük sorunlardan biri yüksek kayma gerilmeleri sonucu kan hücrelerinin deformasyona uğraması ve bunun sonucunda hemoliz meydana gelmesidir (Reul ve Akdis, 2000). Hemoliz oluşumunu önlemek için kalp pompası tasarımında pompa içindeki oluşan kayma gerilmelerinin en düşük seviyede kalmasına dikkat edilmelidir. Kan hücrelerinin dayanabileceği maksimum kayma gerilmesi için genel olarak $400 \mathrm{~Pa}$ seviyesindeki gerilmeler sınır olarak kabul edilmektedir ( $\mathrm{Lu}$ ve diğg., 2001). Kan hücrelerinin hasarı açısından kayma gerilmesinin şiddetinin yanında maruz kalma süreside çok önemlidir (Yen ve diğ., 2014). Dönel kan pompaları içinde eksenel pompalar küçük boyut ve boru tipinde olmasından dolayı büyük ilgi uyandırmıştır. Ancak eksenel kan pompalarının yüksek dönme hızından dolayı kırmızı kan hücrelerine hasar verme riski yüksektir. Santrifüj pompalar kan hücrelerine daha az hasar vericidir ve daha güvenlidir (Leme ve diğ., 2013).

Bu çalışmada tasarlanan karışık akışılı kalp pompasının başlangıç tasarım değerleri $10000 \mathrm{dev} / \mathrm{dak}$ dönme hızı, $5 \mathrm{~L} /$ dak debi ve $100 \mathrm{~mm}-\mathrm{Hg}$ basınç farkıdır. Yetişkin bir insan için istirahat halindeki nominal aortik basınç $100 \mathrm{~mm}-\mathrm{Hg}$ pompa yükü ve nominal kan ihtiyacı $5 \mathrm{~L} /$ dak debidir (Behbahani ve diğ., 2009). Bu çalışmanın ana amacı, hazır pompa tasarım programları ile tasarlanan kalp destek pompası performansını sayısal ve deneysel olarak belirlemek ve sonuçları karşılaştırmaktır. Çalışmanın bir diğer amacı da milin çarkı emme tarafından ya da basma tarafından tahrik etme durumunun 
pompanın basma yüksekliğine ve akış çizgilerine etkisinin olup olmadığının incelenmesidir. Kalp pompalarının tasarımları aşamasında hesaplamalı akışkanlar dinamiği metotları sayesinde karşılaşılabilecek olumsuzluklara karşı önlemler alınıp iyileştirmeler yapılabilmektedir. HAD, bize üretim öncesi pompanın hem hidrolik özelliklerini inceleme fırsatı hem de kan hasarı olup olmadığını inceleme fırsatı sunmaktadır. HAD çalışmaları ile pompanın akış çizgileri incelenmiş ve geri akış olup olmadığı gözlenmiştir. HAD verileri kullanılarak pompa hidrolik verimi hesaplanmış ve pompa performans eğrisi oluşturulmuştur.

\section{MATERYAL VE METOD (MATERIAL and METHOD)}

\section{Geometrik Model (Geometric Model)}

$\mathrm{Bu}$ çalışmada geometrik tasarım için ANSYS BladeGen, ANSYS Vista CPD ve Solidworks programları kullanıldı. Bir pompanın tasarımının yapılabilmesi için debi, devir ve manometrik basma yüksekliğinin bilinmesi yeterlidir. ANSYS programına başlangıç tasarım değerleri girilerek herhangi bir turbo makine tasarlanabilir. ANSYS programı kanat sayısı, kanat açısı, örtü tipi gibi çarkın tüm özelliklerinde değişiklik yapma olanağını bize sunar. ANSYS programı kalp pompaları gibi mini pompa elemanlarının oluşturulmasına olanak sağlamamaktadır bu sebeple bu çalışmada kullanılan çark ve difüzör olduğundan çok büyük olarak oluşturuldu ve daha sonra ölçeklendirme (benzerlik kuralları) ile uygun boyutlara indirgendi. ANSYS programı ile oluşturulan çark ve difüzör Şekil 1'de görülmektedir. Çarkın geometrik düzenlemeleri, değişiklikleri ve montajı için Solidworks programı kullanıldı. Geometrik tasarım HAD çalışmaları ile eşzamanlı olarak yürütüldü ve toplam 15 denemeden sonra uygun çark ve difüzör tasarımı tamamlandı.

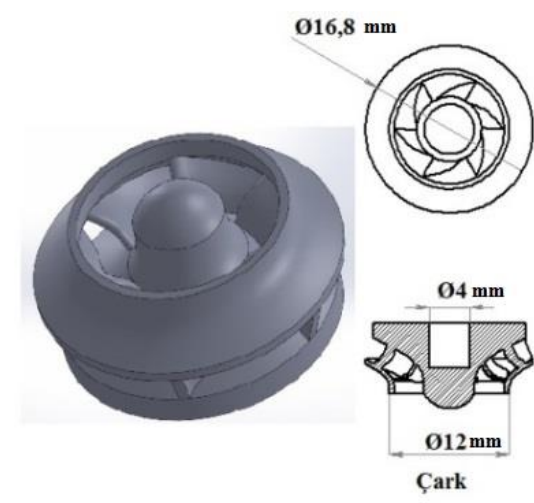

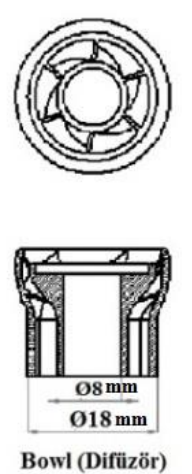

Bowl (Difüzör)

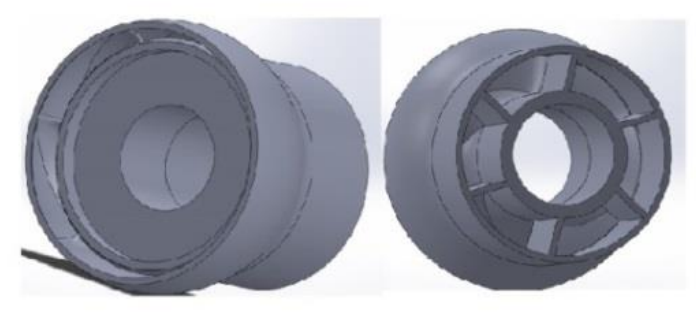

Şekil 1. Tamamlanan çark ve difüzör tasarımı

Figure 1. Completed design of impeller and diffuser

Pompa çarkı $11 \mathrm{~mm}$ emme (giriş) çapına ve $16 \mathrm{~mm}$ çark çapına sahiptir. Kanat sayısı 6 ve kanat profili 3 boyutludur. Çarkın örtü kalınlığı 0,6 mm'dir. Kanat kalınlığ 0,6 mm'dir. Kanat çıkış açısı 89 derecedir. Çarkın göbeğine akışın çarka düzgün bir şekilde (girdapsız) girmesi için Şekil 1'de görüldüğü gibi küçük bir kubbe verilmiştir. Pompa çarkına ait kanadın, göbek ve örtü arasındaki açılarının değişimi Şekil 2'de verilmiştir. Çark kanadına ait hız üçgenleri tasarım için kullanılan programdan alınarak, Şekil 3'de verilmiştir. 


\begin{tabular}{|l|c|c|}
\hline & $\beta_{1}{ }^{\circ}$ & $\beta 2^{\circ}$ \\
\hline 1 (Göbek) & 53 & 85 \\
\hline 2 & 46 & 86 \\
\hline 3 (Orta) & 39 & 87 \\
\hline 4 & 32 & 88 \\
\hline 5 (Örtü) & 25 & 89 \\
\hline
\end{tabular}

Şekil 2. Çark kanat açılarının örtü ile göbek arasındaki değişimi

Figure 2. The change of the impeller blade angle between the shroud and the hub

Çark tasarımı tamamlandıktan sonra bu çarka uygun difüzör tasarımı yapıldı. Difüzör tasarımı için yine ANSYS ve Solidworks programları kullanıldı. Pompa tasarımındaki ana amaçlardan birisi de pompa boyutlarının kompakt ve boru tipinde olması idi. Bu amacı karşılamak için Şekil 1'de görülen bowl (çanak tipi) difüzör tasarlandı. Bowl genellikle dikey türbin su pompalarında kullanılır.

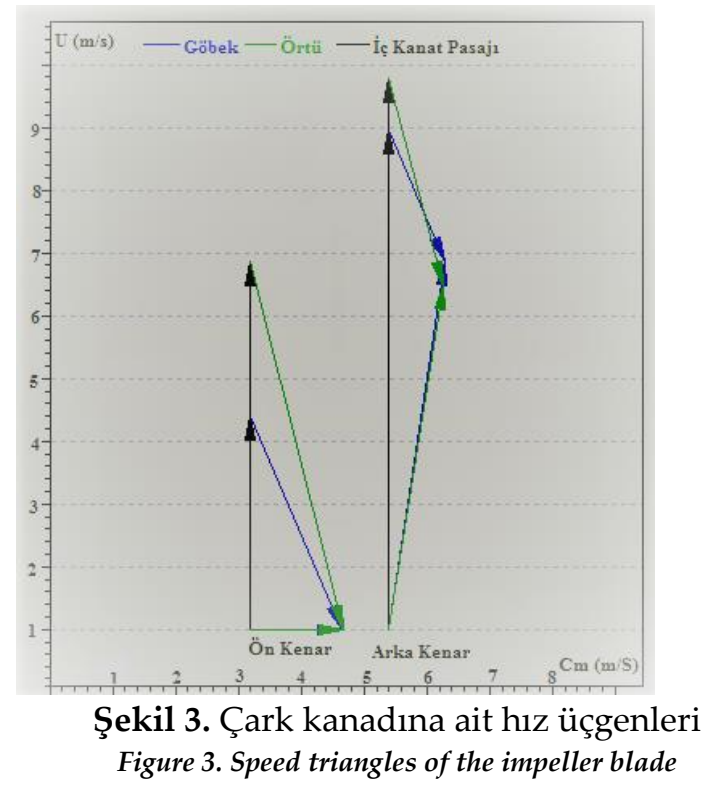

Literatürde ki benzer radyal çarka sahip kan pompalarında, akışkan çarka eksenel yönde girip, radyal yönde (çarka göre) yâda radyal-eksenel karışımı olacak şekilde çıkmaktadır. Bu çalışmada tasarlanan pompada, akışkan çarka eksenel yönde girip bowl tipi difüzör sayesinde yine eksenel yönde çıkmaktadır. Bu özelliğgi ile tasarlanan pompa yeni bir tipte kan pompasıdır. Bowl'un amacı çarktan ayrılan akışkanın yönünü değiştirmek ve dönme ekseni boyunca akmasını sağlamaktır. Bowl, sürtünme kayıplarını arttırmamak için çok uzun olmamalıdır. Ancak akışın çevresel-eksenel yönünü sadece eksenel yöne dönüştürebilmesi için yeterli uzunlukta olmalıdır. Bowl tasarımı yapılırken bowl içindeki kayıplar en az sevide tutularak Şekil 1'de görüldüğü gibi tasarım tamamlandı.

Çarkın ve difüzörün içinde çalışabileceği gövde Solidworks programında tasarlandı. Gövde ile birlikte diğer tüm elemanlar Şekil 4'de görülmektedir. Bu gövde kalıp şeklinde alt ve üst olmak üzere iki parçadan oluşturuldu. Gövdenin alt ve üst kısmı M8 cıvatalarla birbirine bağlandı. Deney sırasında sızdırmazlığı sağlamak için alt gövde üzerine O-ring kanalı açıldı. Mil boyunca sızdırmazlığı sağlamak için yaylı keçe kullanıldı. 


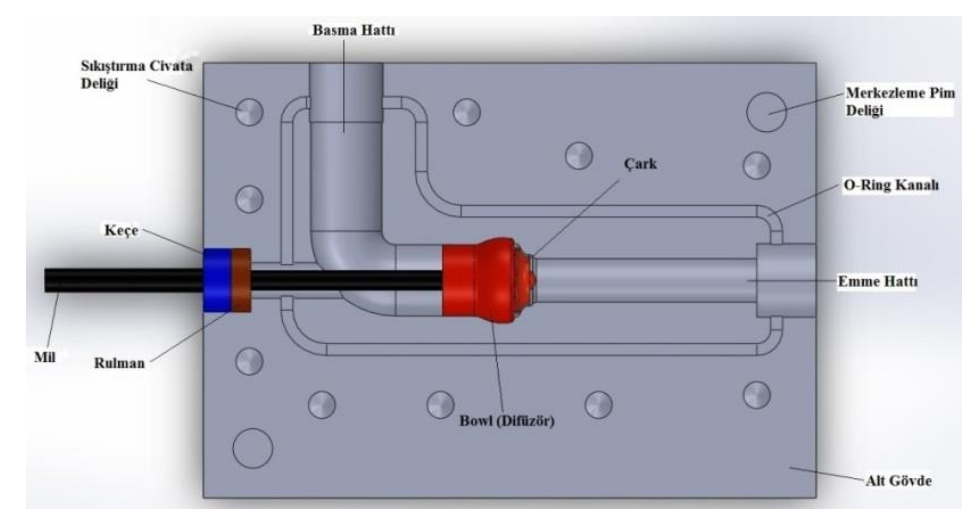

Şekil 4. Çark, difüzör ve diğer elemanların montaj hali Figure 4. Assembly of impeller, diffuser and other elements

$\mathrm{Bu}$ çalışmanın amaçlarından biri de pompa çarkını giriş kısmından ya da çıkış kısmından tahrik etmenin pompa performansına ve akış çizgisine etkisini incelemektir. Bu sebeple Şekil 5'de görüldüğü gibi iki farklı tasarım yapıldı ve HAD ile analiz edilerek hidrolik özelliklerin debiye göre değişimi gözlendi.

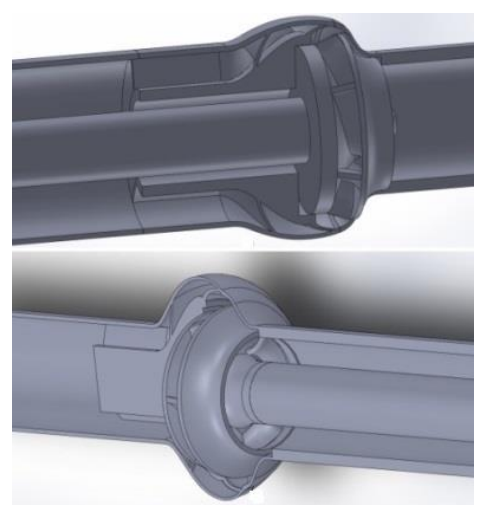

Şekil 5. Basma kısmından tahrikli tasarım ve emme kısmından tahrikli tasarım

Figure 5. Two different designs according to drive location

\section{HAD Simülasyonu (CFD Simulation)}

$\mathrm{Bu}$ çalışmada HAD analizi, pompanın hidrolik performansını iyileştirmek, akış yolu geometrisini iyileştirmek ve kayma gerilmesini azaltmak için etkili bir şekilde kullanıldı. HAD analizleri ticari paket programı ANSYS Fluent ile yürütüldü. HAD analizleri girişten tahrikli ve çıkıştan tahrikli iki sistem içinde aynı şartlar altında yapıldı. Her iki tasarım için tüm sonuçlar benzerlik gösterdi. Sonuçlar arasındaki farkın az olması ve tasarım kolaylığı açısından prototip üretimi için çıkıştan tahrikli tasarım seçildi. Seçilen tasarıma ait HAD 'den elde edilen akış çizgileri Şekil 6' da görülmektedir. HAD sonuçları incelendiğinde tasarımda geri akış görülmedi. HAD analizlerin de akışkan olarak su kullanıldı. Daha sonra Fluent programı içinde suyun özellikleri; yoğunluk $1050 \mathrm{~kg} / \mathrm{m}^{3}$, viskozite 0,0035 Pa.s olacak şekilde değiştirilerek HAD analizleri tekrarlandı. Suyun yoğunluğu ve viskozitesi bu şekilde değiştirilerek kana daha çok benzetildi (Untaroiu ve diğ., 2005; Gardiner ve diğ., 2007; Zhang ve diğ., 2007; Chua ve Su, 2011; Leme ve diğ., 2013). HAD çalışmaları sırasında Skewness ve Orthogonal Quality değerlerinin Fluent programının sunduğu aralıkta kalmasına dikkat edildi. 


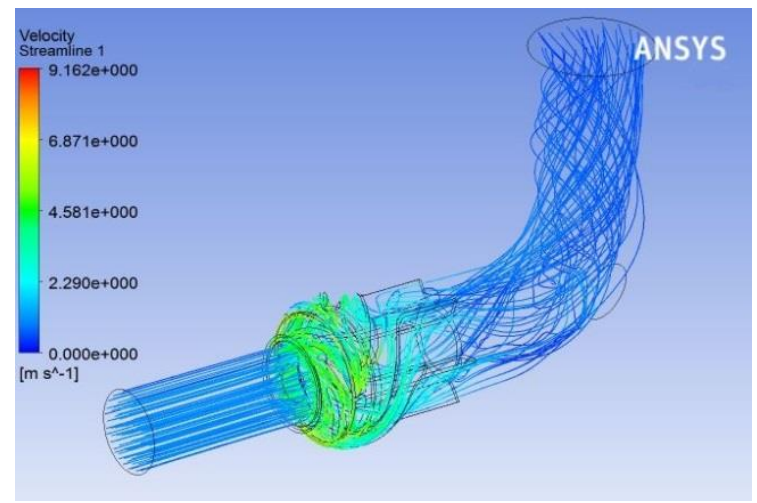

Şekil 6. HAD 'den elde edilen akış çizgileri Figure 6. Flow lines obtained by CFD

HAD analizleri için pompa çarkı ve difüzörün içinde çalışacağı bir gövde modeli hazırlandı. Hazırlanan model için Fine 94 derecesinde çözüm ağı oluşturuldu. HAD çalışmalarındaki sonuçların çözüm ağı hücre sayısına bağlılığını tespit etmek için çözüm ağı bağımsızlık testi yapıldı. Bu testin sonuçları Şekil 7 ve Şekil 8'de verilmiştir. Bu testin sonucunda yaklaşık 1 milyon çözüm ağı hücre sayısından sonra basınç farkı ve tork değişiminin \%1'in altına indiği görüldü ve diğer analizlerin 1090588 hücre sayısında yapılmasına karar verildi.

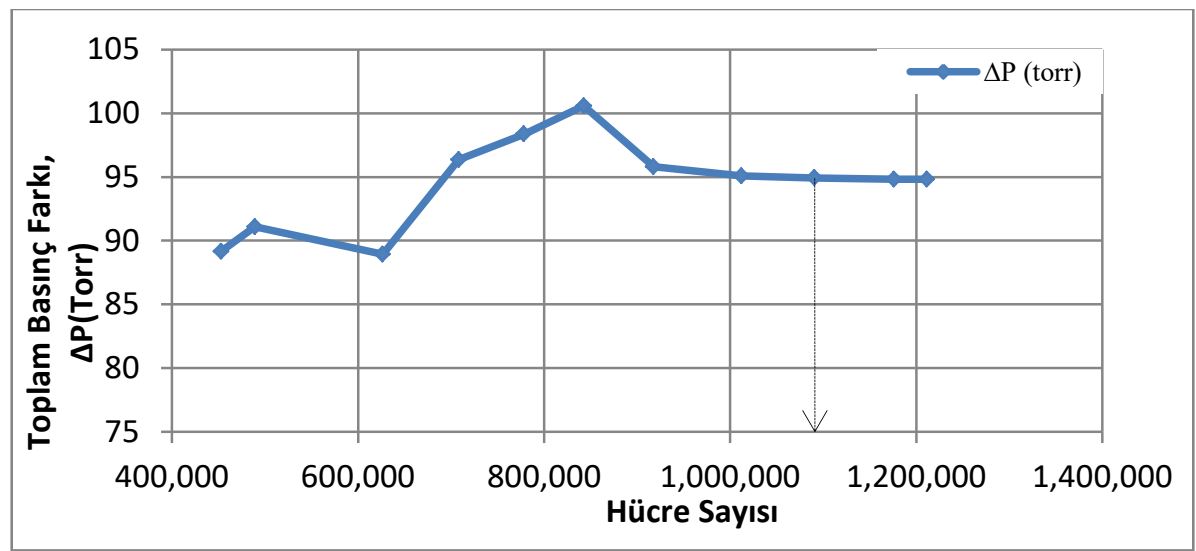

Şekil 7. Hücre sayısı ve basınç farkı arasındaki ilişki

Figure 7. Relationship between cell number and pressure difference

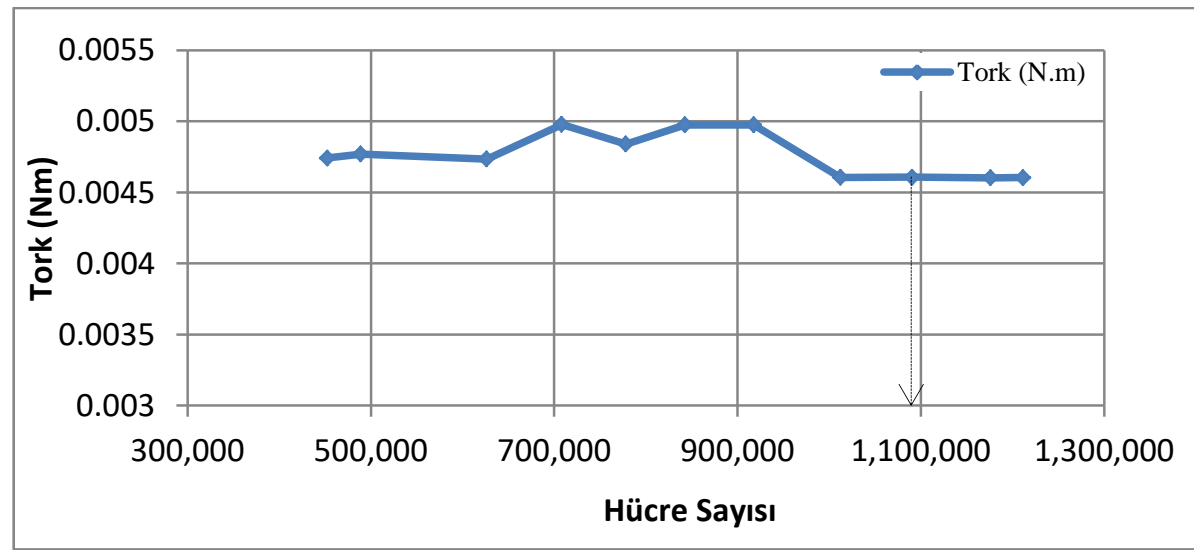

Şekil 8. Hücre sayısı ve tork arasındaki ilişki

Figure 8. Relationship between cell number and torque 
Akışın Reynolds sayısının tasarım noktasında 4000'den büyük olduğu ve tasarım noktasının altındaki debilerde 2300-4000 geçiş bölgesinde kaldığı gözledi. ANSYS Fluent'te çözüm modeli olarak Transition k-kl-omega (3 eqn.) ve Transition SST (4 eqn.) modellerinin kullanılabileceği öngörüldü (Fluent, 2009; Chua ve Su, 2011). Ancak yine de k-omega(2 Eqn), Transition k-kl-omega (3 Eqn) ve Transition SST(4 Eqn) olmak üzere üç model için çeşitli debilerde simülasyonlar yapıldı. Her üç model içinde sonuçlarda kararsızlık olmadı ve yaklaşık aynı sonuçlar elde edildi. Transition k-kl-omega modeli ile yapılan çözümler daha hızlı sonuç verdi ve daha iyi yakınsadı. Ayrıca tasarım noktasının üstündeki debilerde, bu modelin sonuçlarının deneysel sonuçlara daha yakın olduğu görüldü. Bu sebeplerden dolayı diğer tüm analizlerde Transition k-kl-omega (3 eqn.) modeli kullanıldı. Türbülans model seçiminin sonuçlara etkisi Şekil 9'da verilmiştir.

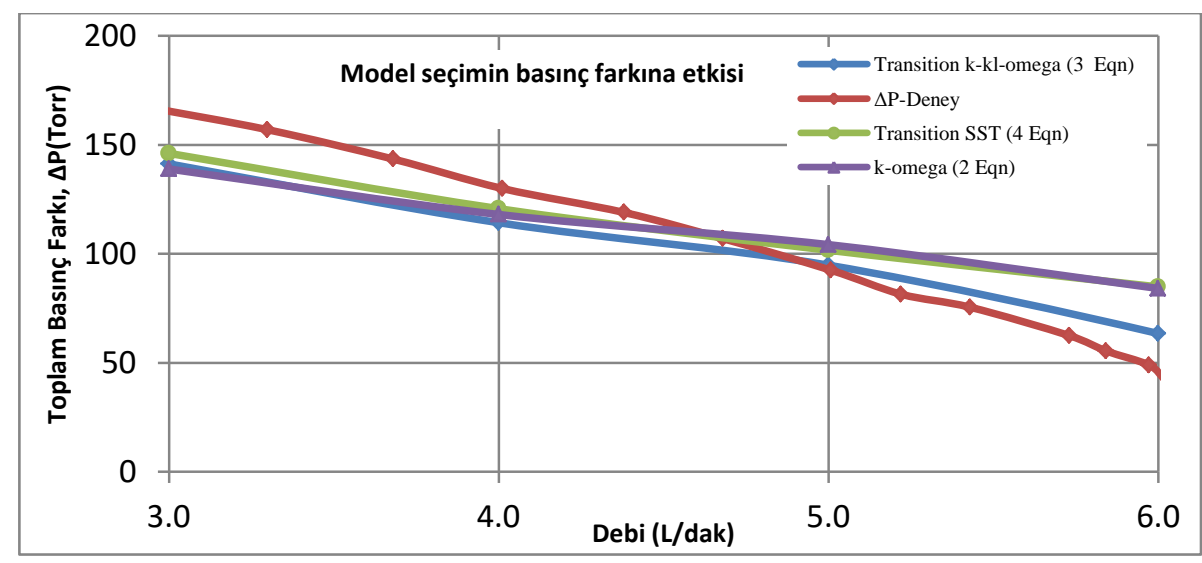

Şekil 9. Türbülans model seçiminin toplam basınç farkı sonucuna etkisi

Figure 9. Effect of turbulence model selection on total pressure difference

Transition k-kl-omega modeli kullanılarak sabit 10000 dev/dak. dönme hızında 1-7 litre/dak. arasında 8 farklı noktada çözümler yapıldı. Çözücü tipi basınç temelli ve daimi olarak ayarlandı. Fluent çözücüsünde giriş şartları olarak 1-7 litre/dak. arasındaki debiler ve 10,5 mm hidrolik çap kullanıldı. Çıkış şartı olarak 100 torr basınç ve 10,5 mm hidrolik çap girildi. Yakınsama, 0,001 seviyelerine geldiğinde sonuçlarda kararlılık olduğu gözlendi. Çözüm yakınsama kriteri olarak daha güvenilir bir sonuç elde etmek amacıyla Fluent çözümlerinde; continuity, x-velocity, y-velocity, z-velocity, k, omega, intermit, retheta değerlerinin hepsi için 0,0001 derecesinde yakınsama kriteri kullanıldı. HAD sonuçlarını değerlendirmek için aşağıdaki denklemler kullanıldı.

Pompaya giriş ve çıkışta türbülans şiddetini tanımlamak için;

$$
\mathrm{TI}=0,16 * \mathrm{Re}^{-1 / 8}
$$

bağıntısı kullanıldı.

Pompa performans eğrisi oluşturulmak için kullanılan parametrelerden:

Toplam basınç farkı;

$\Delta \mathrm{P}_{\mathrm{t}}=\mathrm{P}_{\mathrm{tc}}-\mathrm{P}_{\mathrm{tg}}$

Buradaki toplam basınç;

$$
\mathrm{P}_{\mathrm{t}}=\mathrm{P}+\rho * \frac{\mathrm{V}^{2}}{2}
$$

Pompa çarkının gücü;

$$
\mathrm{N}_{\mathrm{c}}=\mathrm{T} * \omega
$$


Akışkana aktarılan güç;

$\mathrm{N}_{\mathrm{a}}=\Delta \mathrm{P}_{\mathrm{t}} * \mathrm{Q}$

Pompanin mil gücü;

$\mathrm{N}_{\mathrm{m}}=\mathrm{N}_{\text {mot,yükte }}-\mathrm{N}_{\text {mot,boşta }}$

Pompa hidrolik verimi;

$\eta_{\mathrm{h}}=\frac{\Delta \mathrm{P}_{\mathrm{t}} * \mathrm{Q}}{\mathrm{N}_{\mathrm{c}}}=\frac{\mathrm{N}_{\mathrm{a}}}{\mathrm{N}_{\mathrm{c}}}$

Pompa verimi;

$\eta_{p}=\frac{N_{a}}{N_{m}}$

Formülleriyle hesapland1.

\section{Deneysel Yöntem (Experimental Method)}

Deneyin ilk aşamasında akışkan olarak su kullanıldı. Sabit 10000 dev/dak dönme hızında 2-6,5 L/dak debi aralığında basınç vanası kısılarak 15 farklı noktada debi ölçümleri yapıldı. Deneyin ikinci aşamasında akışkan olarak kana daha çok benzetilmesi amacıyla hacimce \%40 gliserin-\%60 su çözeltisi (Untaroiu ve diğ., 2005) kullanıldı. Bu çözelti için de 2-5,5 L/dak debi aralığında 12 noktada ölçümler yapild1.

Pompa tasarım programı ile katı modeli oluşturulan pompa çarkı ve difüzör, lazer sinterleme teknolojisi ile Pa2200 (\%100 naylon) malzemeden üretildi. Üretilen çark ve difüzörün fotoğrafı Şekil 10'da görülmektedir. Pompa çarkı ve difüzörün içinde çalışacağ1 pompa gövdesi alüminyum malzemeden CNC dik işlem merkeziyle üretildi. Pompa gövdesi kalıp mantığıyla iki farklı parça şeklinde imal edildi. Gövdenin iki kısmı arasındaki sızdırmazlığı sağlamak amacıyla gövdenin bir yarısına O-ring kanalı açıldı. Pompa mili paslanmaz çelik malzemeden CNC torna tezgâhında üretildi. Mil boyunda sızdırmazlığı sağlamak için 6X16X7 mm boyutunda yaylı döner mil keçesi kullanıldı. Milin yataklanması için kapaklı 625 rulmanı kullanıldı. Kurulan deney düzeneğinin şematik gösterimi Şekil 11 'de verilmiştir.

Yaklaşık 12 litre hacme sahip ve atmosfere açık bir kap akışkan deposu olarak kullanıldı. Depodan pompa gövdesine giriş ve çıkışlar için 10,5 mm çapında şeffaf ve esnek bir boru kullanıldı. Boşaltma hattının sonuna doğru debi ayarı yapmak için bir vana konuldu. Deneyde akışkanın debisini ölçmek için $20 \mathrm{ml}$ hassasiyetli dereceli kap kullanıldı. Debi ölçümü sırasında akışkanın yönü değiştirilerek akışkan dereceli kaba yönlendirildi. Bir kronometre ile suyun alınma zamanı ve dereceli kapta biriken hacmi ölçülerek debi hesaplandi.

Motor dönme hızının ölçümü motor ile pompa milinin bağlantısı üzerine takılan endüktif proximity sensörüyle yapıldı. Motor devir sayacı olarak Sick IME1603 endüktif proximity sensör kullanıldı. Bu sensörün doğrulaması \%0,05 ölçme hassasiyetine sahip Lutron DT2236 dijittal foto takometre ile yapıldı. Deneyde güç ölçümü dijital göstergeli wattmetre ile yapıldı. Basınç ölçümlerini yapabilmek için emme ve basma hattına üzerlerinde $2 \mathrm{~mm}$ çapında delikler bulunan alüminyum bloklar imal edilip takıldı. Bu bloklara $2 \mathrm{~mm}$ çapında şeffaf ve esnek borular takılarak akışkan basınç sensörüne iletildi. Basınç ölçümü için \%0,25 ölçüm hassasiyetine sahip Valcom 27D sensörü kullanıldı. Basınç ayarlanması emme ve basma hattına takılan iki adet manometre ile yapıldı. Deney setinin fotoğrafı Şekil 12'de görülmektedir. 


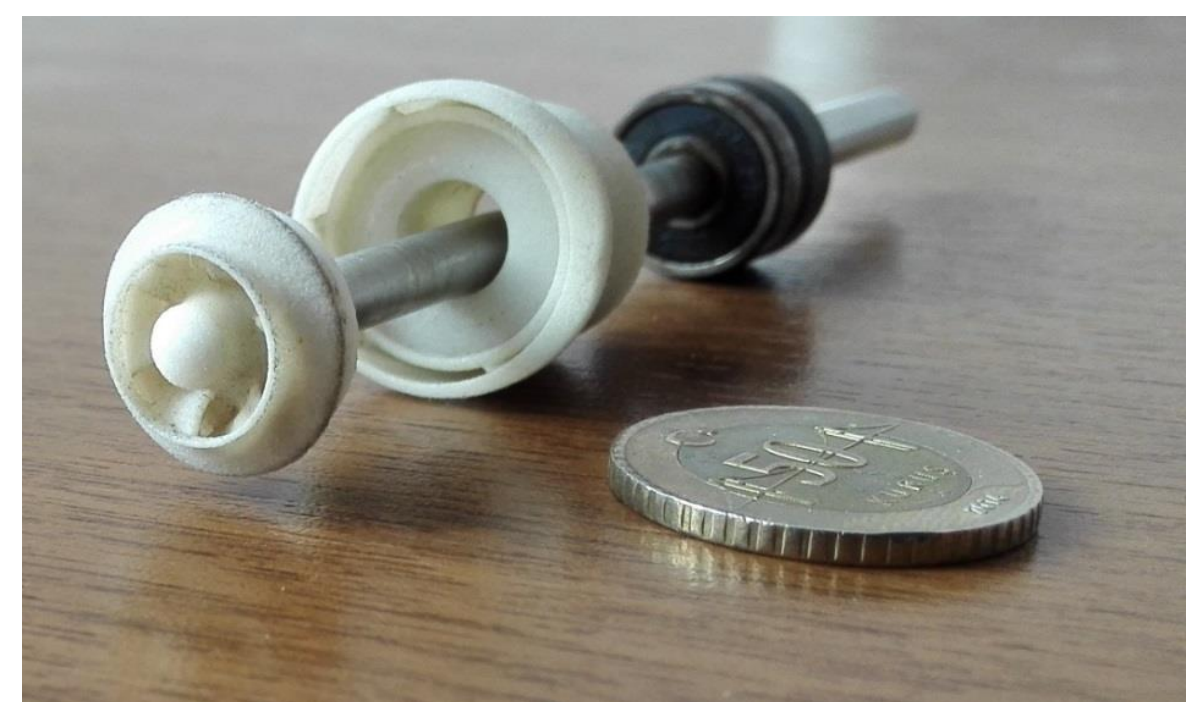

Şekil 10. Lazer sinterleme teknolojisi ile üretilen çark ve difüzörün fotoğrafı Figure 10. Photo of the impeller and diffuser produced by laser sintering technology

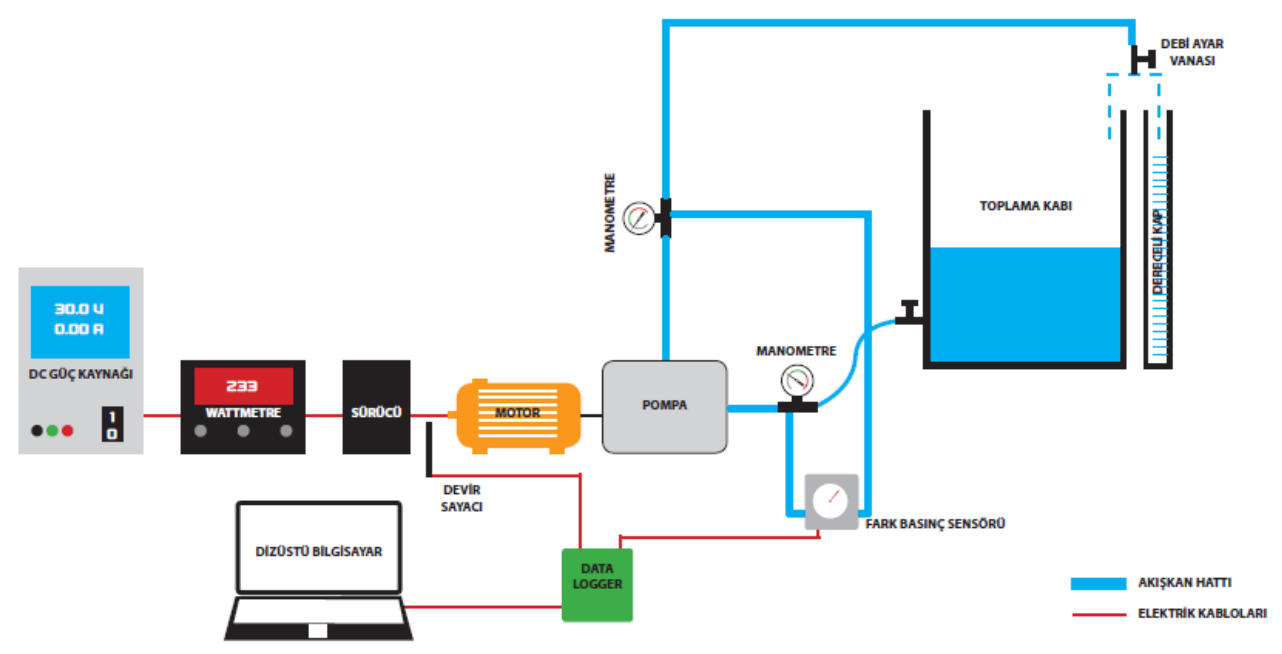

Şekil 11. Kurulan deney düzeneğinin şematik gösterimi

Figure 11. Schematic representation of the experimental setup 


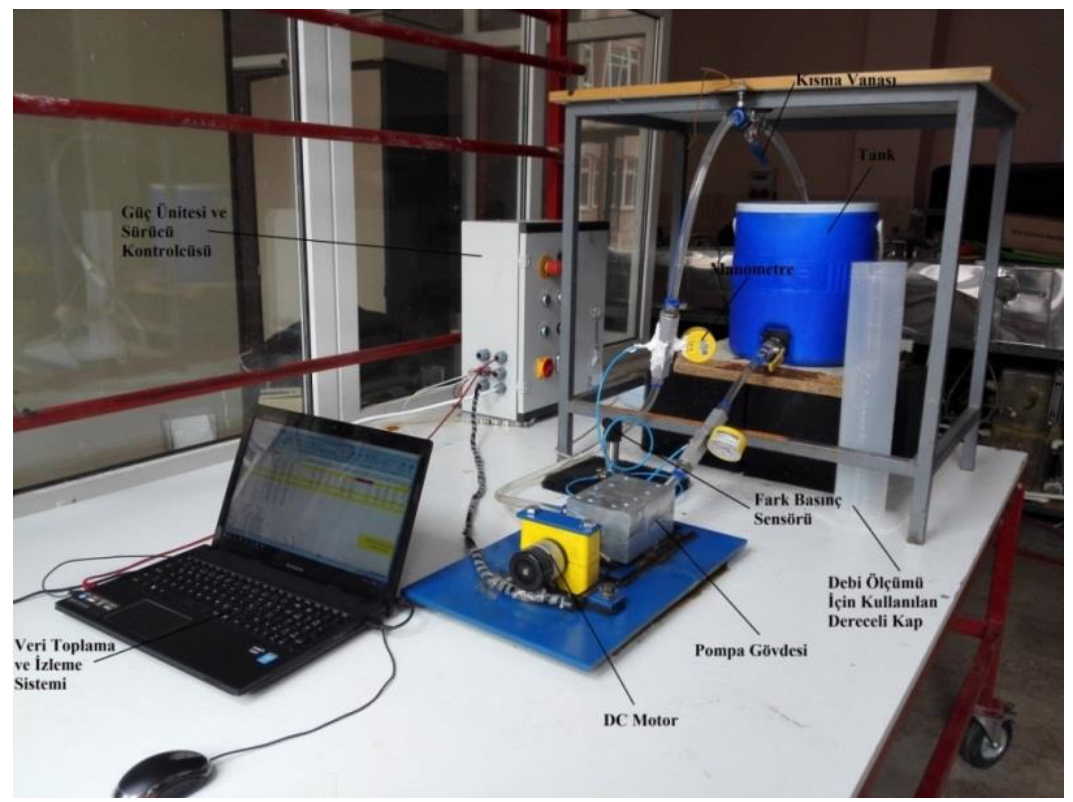

Şekil 12. Kurulan deney düzeneğinin fotoğrafı

Figure 12. Photo of the experimental setup

\section{SAYISAL-DENEYSEL SONUÇLAR ve TARTIŞMA (NUMERICAL-EXPERIMENTAL RESULTS and DISCUSSION)}

Akışkanın su olduğu durumdaki HAD ve deney basınç farklarının karşılaştırılması Şekil 13'de verilmiştir. Bu sonuçlardan görüldüğü üzere, tasarım debisi $5 \mathrm{~L} /$ dak 'da ve tasarım dönme hızı 10000 dev/dak 'da HAD simülasyonu ve deneyin ikisi için de 92 torr basınç farkı elde edilmiştir. HAD ve deney sonuçları arasında iyi bir uyum olduğu gözlenmiştir. Tasarım başlangıç değeri olan 100 torr basınç farkına hem HAD hem de deney için \%8 sapma ile yani 92 torr basınç ile yaklaşılmıştır. Şekil 13 'de görüldüğü üzere tasarım debisinden uzaklaştıkça HAD ve deney arasındaki fark artmaktadır.

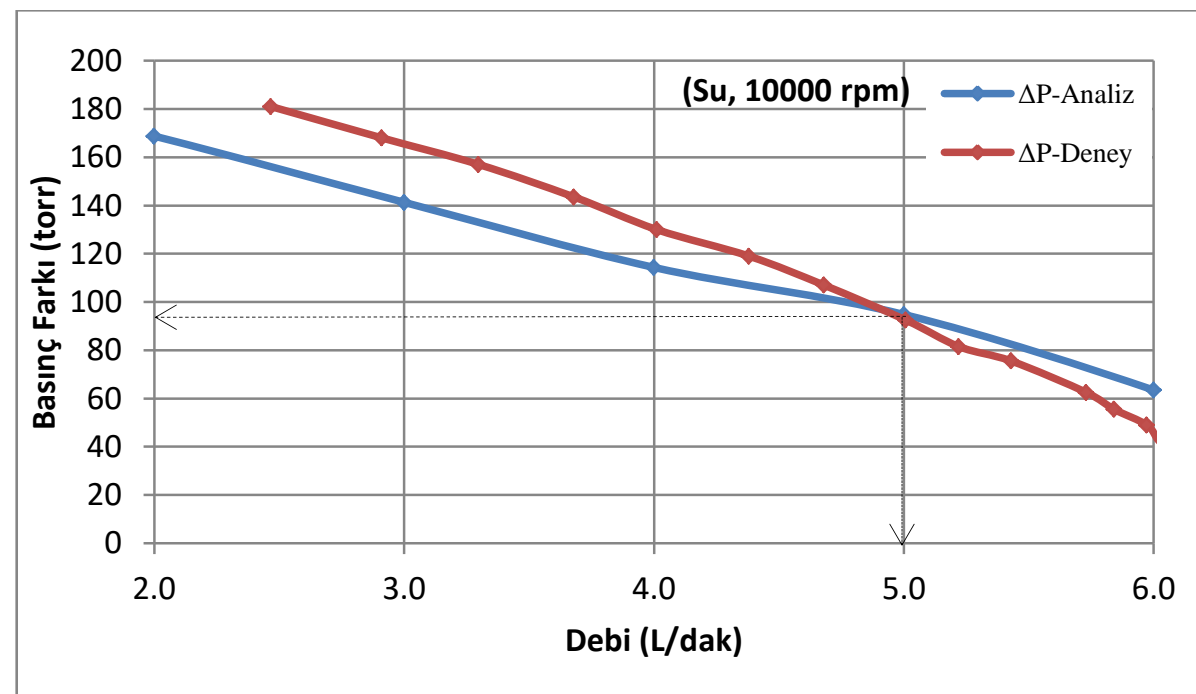

Şekil 13. Su için 10000 dev/dak dönme hızında HAD ve deney basınç farkları karşılaştırılması Figure 13. Comparison of CFD and test pressure differences for water at 10000 rpm rotation speed

Su için 10200 dev/dak dönme hızında 5 L/dak'llk tasarım debisinde 100 torr'luk tasarım basıncına ulaşılmıştır. 10200 devir/dakika dönme hızında HAD ve deney basınç farklarının karşılaştırması Şekil 14'de görülmektedir. 


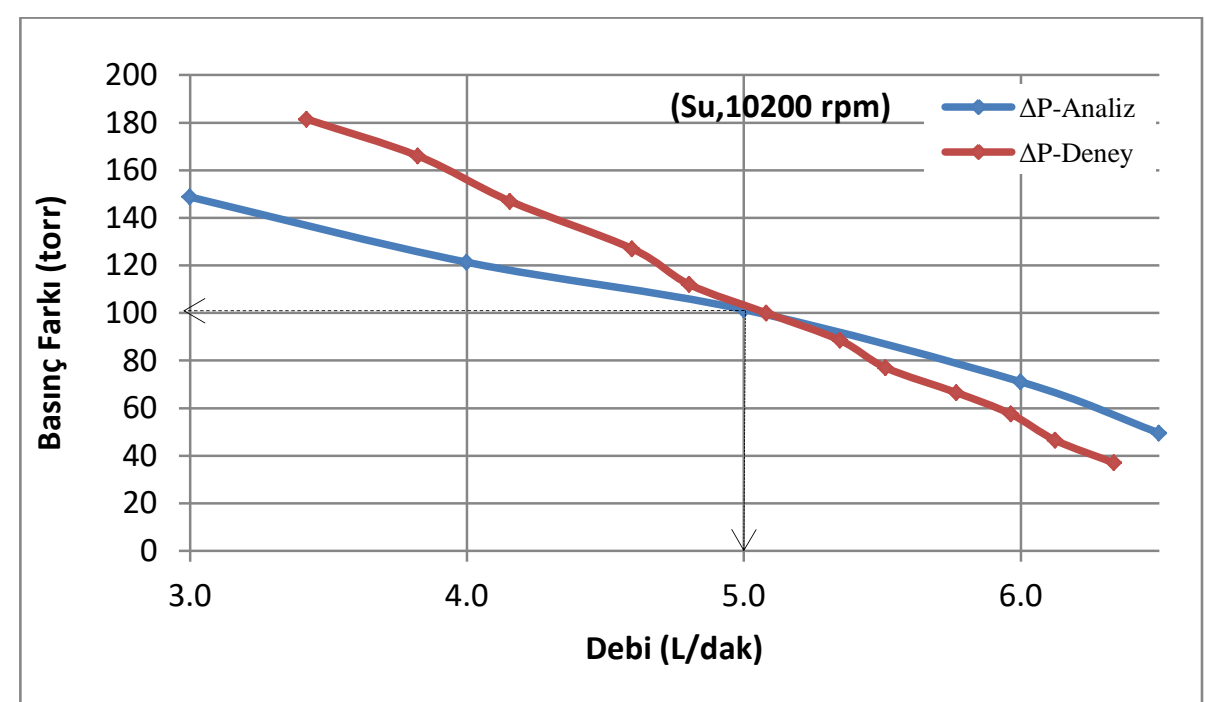

Şekil 14. Su için 10200 dev/dak dönme hızında HAD ve deney basınç farkları karşılaştırması Figure 14. Comparing CFD and experimental pressure differences for water at a rotation speed of $10200 \mathrm{rpm}$

10200 dev/dak dönme hızında tasarım noktasından uzaklaştıkça HAD ve deney sonuçlarının birbirinden uzaklaştığı görülmektedir.

$10000 \mathrm{dev} /$ dak ve $10200 \mathrm{dev} /$ dak dönme hızlarında su-gliserin çözeltisi için HAD ve deney basınç farkları karşılaştırmaları Şekil 15 ve Şekil 16' da verilmiştir. HAD 'de 10000 devir/dakika dönme hızında ve $5 \mathrm{~L} /$ dak debide çözelti için 80 torr basınç farkı elde edilmiştir. Deney 'de 10000 devir/dakika dönme hızında ve $5 \mathrm{~L} /$ dakika debide çözelti için 60 torr basınç farkı elde edilmiştir. HAD 'de 10200 devir/dakika dönme hızında ve $5 \mathrm{~L} /$ dakika debide çözelti için 89 torr basınç farkı elde edilmiştir. Deney 'de 10200 devir/dakika dönme hızında ve $5 \mathrm{~L} /$ dakika debide çözelti için 75 torr basınç farkı elde edilmiştir.

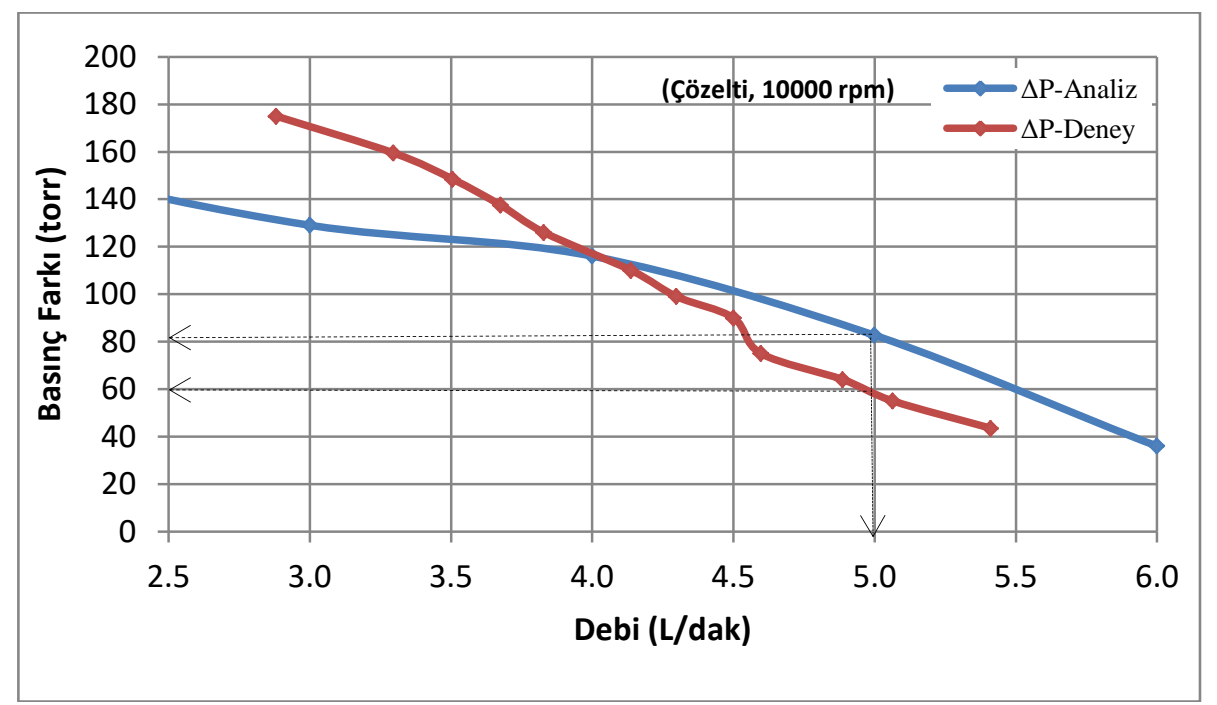

Şekil 15. Çözelti için 10000 dev/dak dönme hızında HAD ve deney basınç farkı karşılaştırması Figure 15. Comparison of CFD and experimental pressure difference at $10000 \mathrm{rpm}$ for solution 


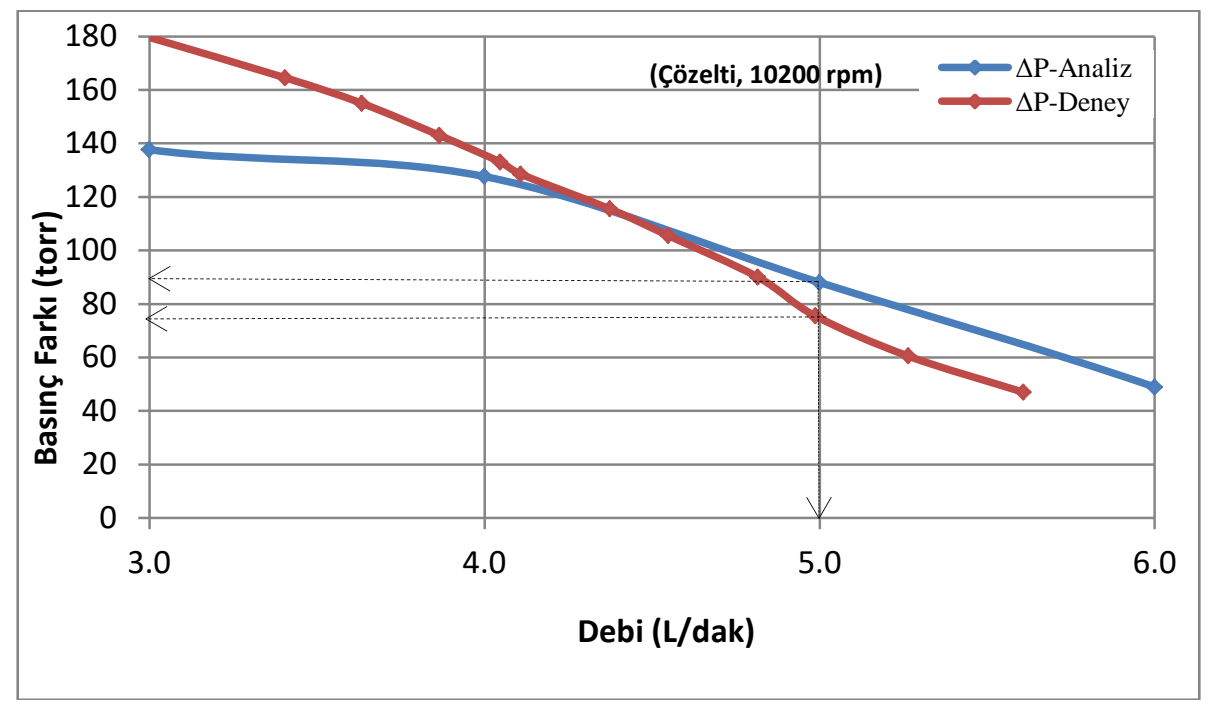

Şekil 16. Çözelti için 10200 dev/dak dönme hızında HAD ve deney basınç farkı karşılaştırması Figure 16. Comparison of CFD and experimental pressure difference at 10200 rpm for solution

Su-gliserin çözeltisi deneyinde, $5 \mathrm{~L} /$ dak tasarım debisinde 100 torr'luk tasarım basıncına 10600 dev/dak dönme hızında ulaşılmıştır.

Bu çalışmada tasarım noktasının üstündeki debilerde deneysel sonuçlar HAD sonuçlarından yüksek çıkmıştır. HAD sonuçlarının deneysel sonuçlardan yüksek çıkması beklenebilir ancak bu her zaman böyle olmak zorunda değildir. Literatürde; Demir ve diğ. (2011), Hsu ve diğ. (2014), Chopski ve diğ. (2016) yapmış olduğu çalışmalarda da benzer durum ile karşılaşılmıştır.

Tasarlanan pompanın tasarım noktasında su için HAD ve deney sonuçları birebir uyuşmuştur. Ancak tasarım noktasından uzaklaştıkça HAD ile deney sonuçları arasındaki fark artmıştır. Su için tasarım dönme hızında HAD ile deney sonuçları arasındaki maksimum sapma \%13 olmuştur. Sugliserin çözeltisi için tasarım dönme hızında ve tasarım debisinde HAD ile deney sonuçları arasında \%25 sapma olmuştur ve maksimum sapma değeri \%27 olmuştur. Sapma hesabı, sabit debide HAD ve deney sonuçları arasındaki farkın mutlak değeri alınıp, yüzde ye dönüştürülerek yapılmıştır. Akışkanın sugliserin olduğu durumda sapma miktarının yüksek çıkmasının, pompanın tasarımının ve hesaplarının suya göre yapılmış olmasından kaynaklandığı düşünülmektedir. Bu çalışmada; deney sonuçları ile HAD sonuçları arasındaki fark su pompaları için yüksektir. Ancak literatürdeki kalp pompaları ile ilgili çalışmalar ile kıyaslandığı zaman makul değerler içinde kalmaktadır. Demir ve diğ. (2011) yapmış olduğu çalışmada, tasarım dönme hızında tasarım noktasında deney ve simülasyon arasında \%9 sapma olmuştur ve maksimum sapma değeri \%17 olmuştur(Akışkan olarak su kullanılmıştır). Aka ve diğ. (2014) yapmış olduğu çalışmada, tasarım noktasında ve tasarım dönme hızında HAD ile deney sonuçları arasında yaklaşı $\% 14,5$ sapma ve maksimum \%18 sapma olduğu görülmüştür. Untaroiu ve diğ. (2005) yapmış olduğu kalp pompası tasarımında; 6000 dev/dak dönme hızında 5 L/dak debide deney ve simülasyon arasında yaklaşık \%8,2 sapma olmuştur. Arvand ve diğ. (2004) yaptığı çalışmada; çark özelliklerine göre 3 farklı tasarım yapmışlardır(A,B ve C olmak üzere) . Bu tasarımlardan A tasarımı için $5 \mathrm{~L} /$ dak ve 6000 dev/dak dönme hızında HAD ve deney arasındaki sapma \% 15'dir. Aynı tasarım için 5 L/dak ve $7000 \mathrm{dev} /$ dak dönme hızında deney ve HAD arasındaki sapma \% 10,4 'dür. B tasarımında 5 L/dak debi için 6000 dev/dak dönme hızında \%9, 7000 dev/dak dönme hızında \%6 ve 8000 dev/dak dönme hızında \%3 sapma olmuştur. C tasarımında $5 \mathrm{~L} /$ dak debi için $7000 \mathrm{dev} / \mathrm{dak}$ dönme hızında $\% 5$ ve $6000 \mathrm{dev} /$ dak dönme hızında \%1 sapma olmuştur. Masuzawa ve diğ. (2009) yaptığı çalışmada 5 L/dak debi ve $1400 \mathrm{dev} /$ dak dönme hızında HAD ve deney arasındaki sapma yaklaşık \%14'dür.

10000 ve $10200 \mathrm{dev} / \mathrm{dak}$ 'da HAD simülasyonu ve deneysel olarak belirlenen verimler, su için Şekil 17 ve su-gliserin çözeltisi için Şekil 18' de hacim debisine bağlı olarak gösterilmiştir. Deneysel sonuçlara göre ifade edilen pompa verimi ( $\eta$ ); pompanın hidrolik, volumetrik ve mekanik verimlerini içermektedir. HAD simülasyonu sonuçlarına göre verilen $(\eta \mathrm{h})$; pompanın sadece hidrolik verimini 
dikkate almaktadır. Bu yüzden verimler arasındaki fark çok büyüktür. HAD simülasyonu sonucuna göre her iki akışkan için de $4 \mathrm{~L} /$ dak debide hidrolik verim maksimum olmaktadır ve değeri \% 19 ila 24 arasındadır. Bu verim büyük ölçekli pompalara göre çok küçüktür; ama bu tür mini pompalar için normal bir değerdir. Arvand ve diğ. (2004) tasarlamış oldukları 3 farklı A,B,C isimli çarklar için HAD yardımıyla sırasıyla \%24, \%31 ve \%34 hidrolik verim elde etmişlerdir. Gardiner ve diğ. (2007) yapmış olduğu çalışmada HAD yoluyla hesaplanan pompa hidrolik verimleri çeşitli debiler için \%10 ile \%16 arasında değişmiştir. Gaddum ve diğ.(2012) farklı dönme hızlarına göre çeşitli tasarımlar yapmışlardır ve bu tasarımların deneysel verimleri \%5 ile \%40 arasında değişmiştir. Hsu ve diğ.(2014) yapmış olduğu çalışmada ise pompanın hem HAD yoluyla hesaplanan hidrolik verimi hem de deneysel yolla hesaplanan genel verimi $\% 1$ ile $\% 10$ arasında değişmiştir. Literatürdeki kalp pompası ile ilgili çalışmaların hidrolik verimi genelde \%15-\%40 arasındadır. Bazı çalışmalarda bu değerin \%15'in altına indiği de görülmüştür.

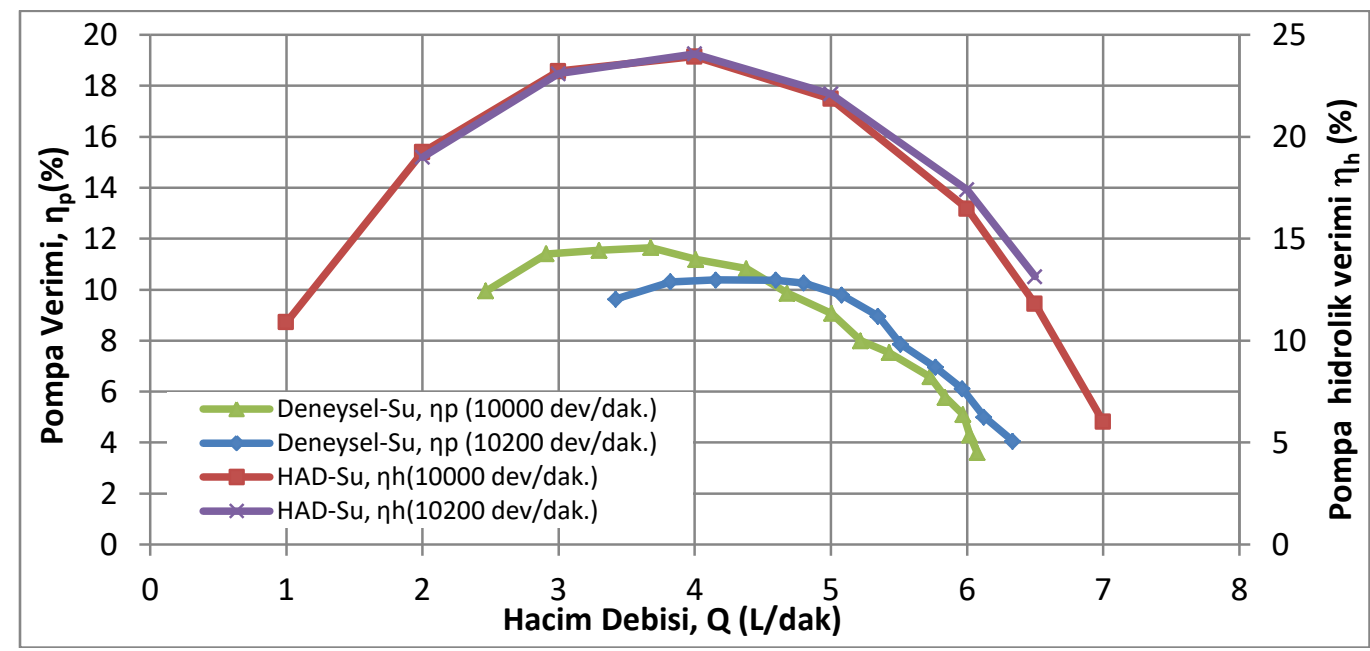

Şekil 17. Su için HAD ve deney verimlerinin karşılaştırılması Figure 17. Comparison of CFD and experimental efficiencies of water

Çok büyük ölçekli rotodinamik (çarklı) pompalarda verim \% 85'in üzerinde olabilmektedir. Burada tasarım debisinde pompanın genel verimi su için \%9-10 ve su-gliserin çözeltisi için yaklaşık \%5 gibi çok küçük değerlere sahiptir. Bu verimler simülasyondaki verimlerle kıyaslandığında görülen büyük farklar, tasarlanan prototip yarı eksenel pompanın mekanik ve volumetrik verimlerinin iyileştirilmesi gerektiğine işaret etmektedir.

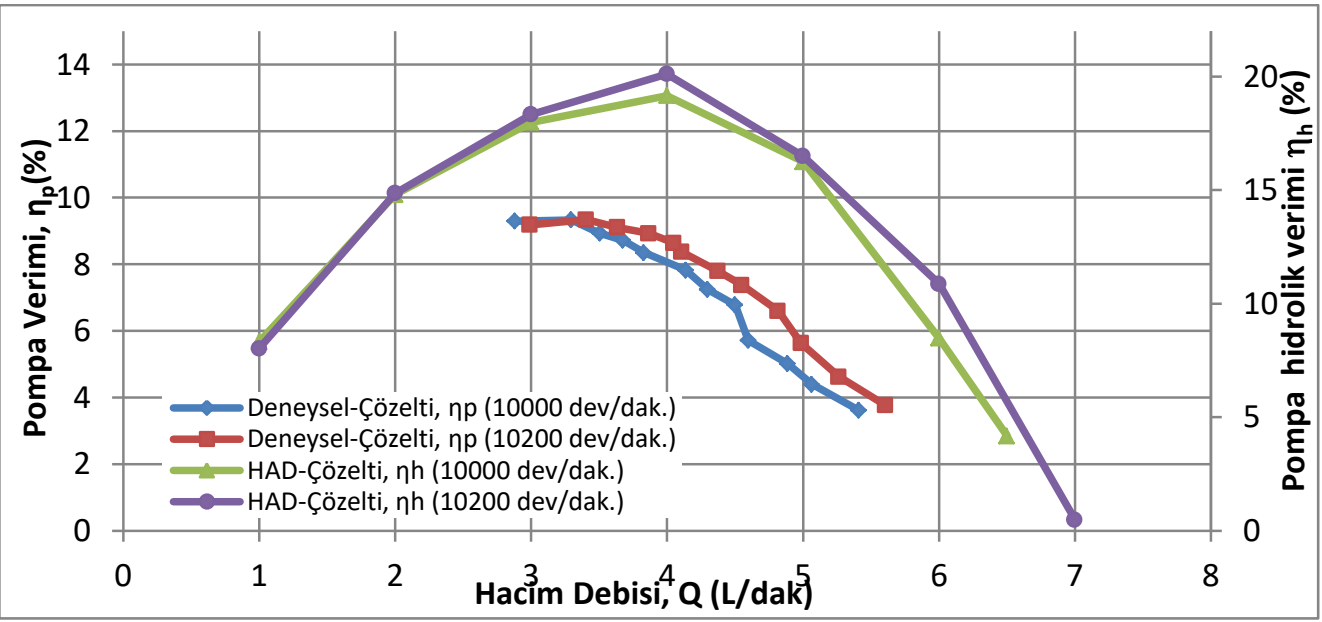

Şekil 18. Çözelti için HAD ve deney verimlerinin karşılaştırılması Figure 18. Comparison of CFD and experimental efficiency for solution 
Akışkan olarak su kullanıldığı zaman pompa içinde meydana gelen kayma gerilmelerinin önemli olduğu bölgeler Şekil 19'da gösterilmiştir. Akışkan su olduğu zaman pompa içinde oluşacak en yüksek kayma gerilmesinin görüldüğü bölge olarak çark kanadının giriş kısmı ve difüzör kanadının giriş kısmı olarak belirlendi. Bu bölgelerde ki görülen en yüksek kayma gerilmesi değeri 1051 Pa'dır. Çark tabanı ile difüzör arasındaki boşluk 0,4 mm yapılarak bu bölgede oluşabilecek yüksek kayma gerilmesinin önüne geçildi. Bu boşluğun 0,3 mm'nin altında olduğu zaman kayma gerilmesinin $460 \mathrm{~Pa}^{\prime}$ ın üzerinde olduğu görüldü.

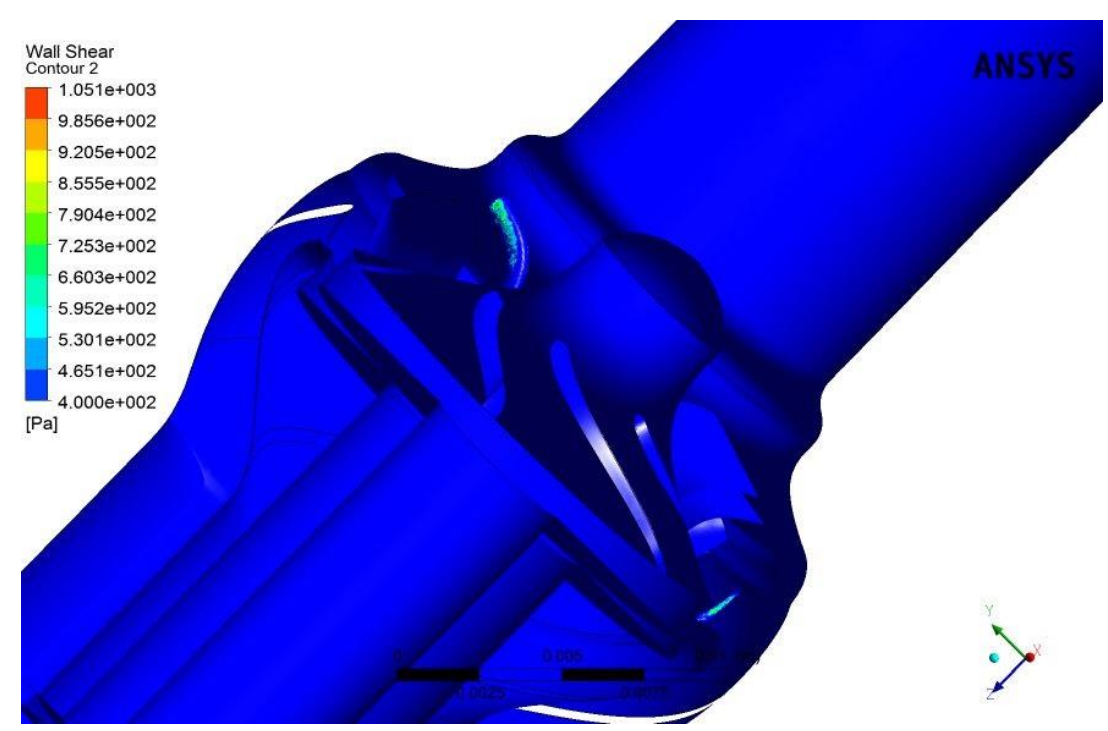

Şekil 19. Su için HAD simülasyonuyla bulunan kayma gerilmeleri

Figure 19. Shear stresses found by CFD simulation for water

Su-gliserin çözeltisi için HAD simülasyonu ile belirlenen kayma gerilmeleri Şekil 20'de görülmektedir. Bu sonuçlara göre kayma gerilmesinin en büyük değeri 2159 Pa'dır. Bu değerin görüldüğü bölge yine çark giriş ucu ve difüzör giriş kısmıdır. Pompa içinde oluşan kayma gerilmelerinin kan hücrelerine zarar verip vermeyeceğini söylemek için tek başına kayma gerilmesi değerinin şiddeti yeterli değildir aynı zamanda akışkanın kayma gerilmesine maruz kalma süresinin de hesap ve analiz edilmesi gereklidir (Yen ve diğ., 2014).

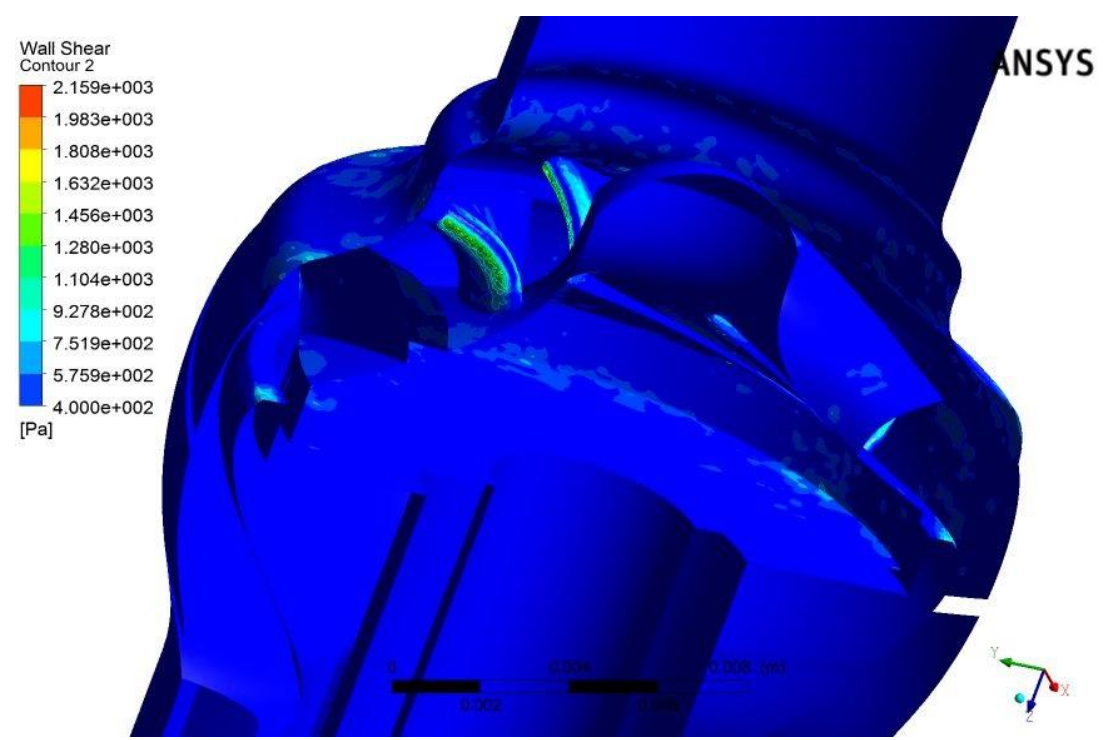

Şekil 20. Su-Gliserin çözeltisi için HAD simülasyonuyla bulunan kayma gerilmeleri Figure 20. Shear stresses of water-glycerin solution found by CFD simulation 


\title{
ARAŞTIRMA SONUÇLARI (RESEARCH RESULTS)
}

Bu çalışmada özgün tasarıma sahip olan yeni bir tipte yarı eksenel kalp destek pompası tasarlanmış, HAD simülasyonu ile performansı belirlenmiş, görülen eksiklere göre katı modeli modifiye edilerek onun prototipi üretilmiştir. Üretilen bu mini pompanın, daha önce kurulan kalp destek pompası test ünitesinde deneysel performansı belirlenmiştir. Başlangıç tasarım değerlerine göre tasarımı yapılan ve prototipi üretilen pompadan ilk olarak beklenen özellik, HAD ve deney çalışmaları ile başlangıç tasarım değerlerinin doğrulamasının yapılabilmesiydi. Su için yapılan HAD ve deneysel çalışmaların ikisinde de tasarım noktasında 92 torr basınç farkı (tasarım basıncından 8 torr eksik) elde edildiği görülmüştür. Tasarım basıncı olan 100 torr'a 10200 dev/dak da ulaşılabilmiştir. Su için tasarım noktasında HAD ve deney sonuçları birebir uyuşmuştur ancak tasarım noktasından uzaklaştıkça HAD ve deney sonuçları arasındaki fark artmıştır. Su-gliserin çözeltisi için HAD ile deneysel sonuçlar arasındaki fark suya göre daha yüksektir. Bu farkın sebebinin pompa tasarımının suya göre yapılmış olmasından kaynaklandığı düşünülmektedir.

Pompa içindeki kayma gerilmelerinin dağılımına baktığımız zaman; çark kanadının giriş kısmı, difüzör kanadının giriş kısmı gibi bazı bölgelerde çok yüksek değerlere çıktığı, diğer bölgelerde ise bunlara göre çok daha düşük seviyelerde olduğu görülmektedir. Pompa içinde oluşan kayma gerilmelerinin kan hücrelerine zarar verip vermeyeceğini tek başına kayma gerilmelerinin büyüklüğüne bakılarak söylenemez. Pompa içindeki kanın hemolize uğrayıp uğramayacağı konusunda akışkanın kayma gerilmesine maruz kalma süreside çok önemlidir. Akışkanın kayma gerilmesine maruz kalma süresisin hesabı ve analizi bu çalışmanın konusu değildir. Kayma gerilmelerini azaltma ve akışkanın maruz kalma süresiyle birlikte değerlendirilmesi başlı başına farklı bir konudur. Bu çalışmada, bir ön fikir oluşturması bakımından HAD den elde edilen kayma gerilme sonuçları verilmiştir. Bu konu üzerine iyileştirmeler gelecek çalışmaların konusu olarak planlanmaktadır.

Bu çalışmada tasarlanan pompanın HAD yoluyla hesaplanan hidrolik verimi literatürdeki pompalar ile kıyaslandığında makul değerler içindedir ancak hidrolik verim ile genel pompa verimi arasındaki fark büyüktür. Bu farkın deney setindeki mekanik sürtünmeler ve küçük sızıntı kaçaklarının ve prototiplerin yüzey pürüzlülügünün sebep olduğu düşünülmektedir. Aynı tasarım üzerinden verim arttırmak için çalışmalar devam etmektedir. Normal su pompalarına göre kalp pompalarının verimi çok düşüktür. Kalp pompalarının verimden ziyade istenen basıncı ve debiyi sağlaması daha önceliklidir.

Bundan sonraki çalışmalarda aynı tasarım üzerinden çalışmalara devam ederek; monoblok tasarım, manyetik yataklama, kayma gerilmelerinin düşürülmesi ve akışkanın bu gerilmelere maruz kalma süresinin hesabı, pompa performans iyileştirmeleri gibi konular üzerine olacaktır.

\section{TEŞEKKÜRLER (ACKNOWLEDGEMENT)}

Bu çalışma Selçuk Üniversitesi BAP Koordinatörlüğü tarafından 16201105 numaralı proje kapsamında desteklenmiştir.

\section{SEMBOLLER (NOTATION)}

\author{
Na: Güç (Akışkan) \\ $\mathrm{N}_{\mathrm{m}}$ : Güç (Mil) \\ $\mathrm{N}_{\text {ç: }}$ Güç (Çark)

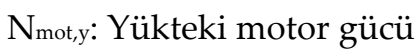 \\ $\mathrm{N}_{\text {mot,b: Boştaki motor gücü }}$ \\ n: Devir (dev/dak) \\ $\eta$ : Verim \\ P: Basınç (Torr) \\ $\Delta \mathrm{P}$ : Toplam basınç farkı (Torr) \\ Re: Reynolds sayısı
}




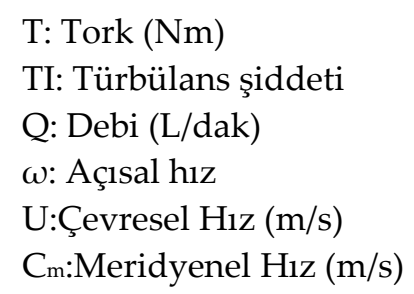

\section{İNDİSLER (INDICES)}
a: Akışkan
b: Boşta
ç: Çıkış
g: Giriş
h: Hidrolik
m: Mil
p: Pompa

\section{KAYNAKLAR (RESOURCES)}

Arvand, A., Hahn, N., Hormes, M., Akdis, M., Martin, M., Reul, H., 2004, "Comparison of Hydraulic and Hemolytic Properties of Different Impeller Designs of an Implantable Rotary Blood Pump by Computational Fluid Dynamics", Artificial Organs, Vol. 28 (10), pp. 892-898.

Behbahani, M., Behr, M., Hormes, M., Steinseifer, U., Arora, D., Coronado, O., Pasquali, M., 2009, "A Review of Computational Fluid Dynamics Analysis of Blood Pumps", European Journal of Applied Mathematics, Vol. 20 (04), pp. 363-397.

Burke, D. J., Burke, E., Parsaie, F., Poirier, V., Butler, K., Thomas, D., Taylor, L., Maher, T., 2001, "The HeartMate II: Design and Development of a Fully Sealed Axial Flow Left Ventricular Assist System", Artificial Organs, Vol. 25 (5), pp. 380-385.

Chopski, S. G., Fox, C. S., Riddle, M. L., McKenna, K. L., Patel, J. P., Rozolis, J. T., Throckmorton, A. L., 2016, "Pressure-Flow Experimental Performance of New Intravascular Blood Pump Designs for Fontan Patients", Artificial Organs, Vol. 40 (3), pp. 233-242.

Chua, L. P., Su, B., 2011, "Numerical Study on The Impeller of an Axial Flow Blood Pump", 2011 4th International Conference on Biomedical Engineering and Informatics (BMEI), 1153-1156.

Demir, O., Biyikli, E., Lazoglu, I., Kucukaksu, S., 2011, "Design of a Centrifugal Blood Pump: Heart Turcica Centrifugal", Artificial Organs, Vol. 35 (7), pp. 720-725.

Fluent, A., 2009, 12.0 Theory Guide, Ansys Inc, 5.

Gaddum, N. R., Fraser, J. F., Timms, D. L., 2012, "Increasing the Transmitted Flow Pulse in a Rotary Left Ventricular Assist Device", Artificial Organs, Vol. 36 (10), pp. 859-867.

Gardiner, J. M., Wu, J., Noh, M. D., Antaki, J. F., Snyder, T. A., Paden, D. B., Paden, B. E., 2007, "Thermal Analysis of the PediaFlow Pediatric Ventricular Assist Device", ASAIO Journal, Vol. 53 (1), pp. 65-73.

Hsu, P.-L., Graefe, R., Boehning, F., Wu, C., Parker, J., Autschbach, R., Schmitz-Rode, T., Steinseifer, U., 2014, "Hydraulic and Hemodynamic Performance of a Minimally İnvasive İntra-Arterial Right Ventricular Assist Device", The International Journal of Artificial Organs, Vol. 37 (9), pp. 697705.

Aka, İ.B., Dadgar, S., Sezer, M.E., Kadıpaşaoğlu, A.K., "Bir Eksenel Akışlı Sol Ventrikül Destek Pompasının (SVDP) Fiziki Performans Testleri İçin Platform Tasarımı" , 14. Tıp Teknolojileri Ulusal Kongresi, Kapadokya, Nevşehir, 25-27 Eylül 2014.

Kim, S. H., Hashi, S., Ishiyama, K., 2012, "Actuation of Novel Blood Pump by Direct Application of Rotating Magnetic Field", IEEE Transactions on Magnetics, Vol. 48 (5), pp. 1869-1874. 
Leme, J., da Silva, C., Fonseca, J., da Silva, B. U., Uebelhart, B., Biscegli, J. F., Andrade, A., 2013, "Centrifugal Blood Pump for Temporary Ventricular Assist Devices With Low Priming and Ceramic Bearings", Artificial Organs, Vol. 37 (11), pp. 942-945.

Lu, P., Lai, H. ve Liu, J., 2001, A Reevaluation and Discussion on The Threshold Limit for Hemolysis in a Turbulent Shear Flow, Journal of Biomechanics, Vol. 34 (10), pp. 1361-1364.

Masuzawa, T., Ohta, A., Tanaka, N., Qian, Y., Tsukiya, T., 2009, "Estimation of Changes in Dynamic Hydraulic Force in a Magnetically Suspended Centrifugal Blood Pump with Transient Computational Fluid Dynamics Analysis", Journal of Artificial Organs, Vol. 12 (3), pp. 150-159.

Eğrican, N., Küçükaksu S., Akgün M., Lazoğlu İ., Cıblak N., An E., Sorgüven E., Şafark K., Okyar F., Uçak C., Şehirlioğlu M., 2010, Minyatür Bir Yapay Kalp Pompa Sisteminin Tasarımı, Analizi ve Prototip Üretimi, Tübitak Projesi, Proje No:106M309, İstanbul

Reul, H. M., Akdis, M., 2000, "Blood Pumps for Circulatory Support, Perfusion, Vol. 15 (4), pp. 295-311.

Taneri, D. B., 2014, "Acil Serviste Acil Tıp Hekimlerinin Organ Bağışı Sürecinde Yönetim, Duyarlılık ve Farkındalıkları", Başkent Üniversitesi Tıp Fakültesi Acil Tıp Anabilim Dalı, Ankara, 20-25.

Untaroiu, A., Wood, H. G., Allaire, P. E., Throckmorton, A. L., Day, S., Patel, S. M., Ellman, P., Tribble, C., Olsen, D. B., 2005, "Computational Design and Experimental Testing of a Novel Axial Flow LVAD, ASAIO Journal, Vol. 51 (6), pp. 702-710.

Wood, H. G., Throckmorton, A. L., Untaroiu, A., Song, X., 2005, "The Medical Physics of Ventricular Assist Devices, Reports on Progress in Physics, Vol. 68 (3), pp. 545-576.

Yen, J. H., Chen, S. F., Chern, M. K., Lu, P. C., 2014, "The Effect of Turbulent Viscous Shear Stress on Red Blood Cell Hemolysis, The Japanese Society for Artificial Organs, Vol. 17 (2), pp.178-185.

Zhang, Y., Xue, S., Gui, X.-m., Sun, H.-s., Zhang, H., Zhu, X.-d., Hu, S.-S., 2007, "A Novel Integrated Rotor of Axial Blood Flow Pump Designed With Computational Fluid Dynamics", Artificial Organs, Vol. 31 (7), pp. 580-585. 